\title{
A CONCAVE-CONVEX QUASILINEAR ELLIPTIC PROBLEM SUBJECT TO A NONLINEAR BOUNDARY CONDITION
}

\author{
José C. SABINA DE LIS
}

Abstract. This paper deals with the existence of a positive solution to the problem

$$
\begin{cases}-\Delta_{p} u+u^{p-1}=u^{r-1}, & x \in \Omega, \\ |\nabla u|^{p-2} \frac{\partial u}{\partial v}=\lambda u^{q-1}, & x \in \partial \Omega,\end{cases}
$$

where $\Omega \subset \mathbb{R}^{N}$ is a bounded domain, $v$ designates the unit outward normal to $\partial \Omega, \Delta_{p}$ is the $p$-Laplacian operator, $1<q<p<r \leqslant p^{*}, p^{*}=N p /(N-p)$ if $p<N, p^{*}=\infty$ otherwise, while $\lambda>0$. Our main result states the existence of $\Lambda>0$ so that positive solutions are only possible when $0<\lambda \leqslant \Lambda$ while the existence of a minimal positive solution is ensured in that range.

Mathematics subject classification (2010): 35J70, 35B32.

Keywords and phrases: variational methods, sub and supersolutions, degenerate diffusion.

\section{REFERENCES}

[1] A. Ambrosetti, H. Brezis, G. Cerami, Combined effects of concave and convex nonlinearities in some elliptic problems, J. Funct. Anal., 122 (1994), 519-543.

[2] A. Ambrosetti, J. García-Azorero, I. Peral, Multiplicity results for some nonlinear elliptic equations, J. Funct. Anal., 137 (1996), 219-242.

[3] H. Brezis, Functional Analysis, Sobolev Spaces and Partial Differential Equations, Springer, New York, 2011.

[4] H. BREZIS, T. KATO, Remarks on the Schrödinger operator with singular complex potentials, J. Math. Pures Appl., 58 (1979), 137-151.

[5] M. CuestA, P. TAKÁČ, A strong comparison principle for positive solutions of degenerate elliptic equations, Differential Integral Equations, 13 (2000), 721-746.

[6] L. Damascelli, Comparison theorems for some quasilinear degenerate elliptic operators and applications to symmetry and monotonicity results, Ann. Inst. H. Poincaré, 15 (1998), 493-576.

[7] J. I. DíAZ, J. E. SAA, Existence et unicité de solutions positives pour certaines équations elliptiques quasilinéaires, C. R. Acad. Sci. Paris Sér. I Math., 305, 2 (1987), 521-524.

[8] P. Drábek, J. Milota, Methods of nonlinear analysis. Applications to differential equations, Birkhäuser, Basel, 2007.

[9] J. García-Azorero, J. Manfredi, I. Peral Alonso, Sobolev versus Hölder local minimizers and global multiplicity for some quasilinear elliptic equations, Comm. Contemp. Maths., 2 (2000), 385-404.

[10] J. García-Azorero, I. Peral, J. D. Rossi, A convex-concave problem with a nonlinear boundary condition, J. Diff. Eqns., 198, 1 (2004), 91-128.

[11] J. García-Melián, J. Rossi, J. Sabina DE Lis, Existence and uniqueness of positive solutions to elliptic problems with sublinear mixed boundary conditions, Commun. Contemp. Math., 11, 4 (2009), 585-613.

[12] J. García-Melián, J. Rossi, J. Sabina de Lis, Limit cases in an elliptic problem with a parameter-dependent boundary condition, Asymptotic Analysis, 73 (2011), 147-168. 
[13] J. GARCía-MElián, J. SABINA DE Lis, Maximum and comparison principles for operators involving the p-Laplacian, J. Math. Anal. Appl., 218 (1998), 49-65.

[14] O. A. LAdyzhens Kaya, N. N. URAL'TSEva, Linear and Quasilinear Elliptic Equations, Academic Press, New York, 1968.

[15] G. Lieberman, Boundary regularity for solutions of degenerate elliptic equations, Nonlinear Anal., 12, 11 (1988), 1203-1219.

[16] P. Lindevist, On the equation $\operatorname{div}\left(|\nabla u|^{p-2} \nabla u\right)+\lambda|u|^{p-2} u=0$, Proc. Amer. Math. Soc., 109, 1 (1990), 157-164.

[17] J. D. Rossi, Elliptic problems with nonlinear boundary conditions and the Sobolev trace theorem, Chapter 5 of Handbook of differential equations: stationary partial differential equations vol. II, pp. 311-406, Elsevier/North-Holland, Amsterdam, 2005.

[18] M. Struwe, Variational methods. Applications to nonlinear partial differential equations and Hamiltonian systems, Springer-Verlag, Berlin, 2008.

[19] J. L. VÁZQUEZ, A strong maximum principle for some quasilinear elliptic equations, Appl. Math. Optim., 12, 3 (1984), 191-202. 